\title{
Huertos en flor
}

Carmen Molina Tamacas

Antropológa y Periodista

Radicada en Estados Unidos

Nueva York está entre los cuatro destinos más importantes para los inmigrantes centroamericanos desde los años 60 . Cientos de miles de hombres y mujeres que dejaron la tierra que los vio nacer, ahora ven sus huertos florecer: hijos profesionales, nietos y hasta bisnietos que aportan al desarrollo de la comunidad hispana en Nueva York. De acuerdo con los censos de población estadounidense de 2000 y 2009, el estado se ubica en el tercer lugar de la migración salvadoreña, después de California y Texas; para los hondureños y guatemaltecos, es el cuarto destino predilecto. En el caso de los hondureños, después de Texas, Florida y California. Para los guatemaltecos, después de California, Florida y Texas.

El flujo migratorio, especialmente del Triángulo Norte de Centroamérica (Guatemala, El Salvador y Honduras), es reciente, comparado con el de otros países pioneros como Puerto Rico, de acuerdo con el estudio "US Immigration Policy and Mexican /Central American Migration Flows: Then and Now, del Migration Policy Institute y el Woodrow Wilson International Center for Scholars".

En 1960 había 6.310 salvadoreños en Nueva York; en 2009 son más de 1.140.000.

Para los mismos años, el flujo de guatemaltecos varió de 5.381 a 789.682. Los hondureños aumentaron de 6.503 a 467.943. Sin embargo, esas cifras podrían crecer dada la gran cantidad de pobladores que viven a la sombra.

Estas son las historias de dos familias - Chávez y Coreas - que comparten un elemento en común: uno de sus miembros apostó todo para darle un porvenir a su familia en tierras lejanas, de inviernos duros y veranos abrasantes. Una versión editada de este artículo fue publicada en el "Suplemento Centroamericano" de octubre de 2012 de El Diario/La Prensa, el periódico hispano más antiguo e influyente de Nueva York.

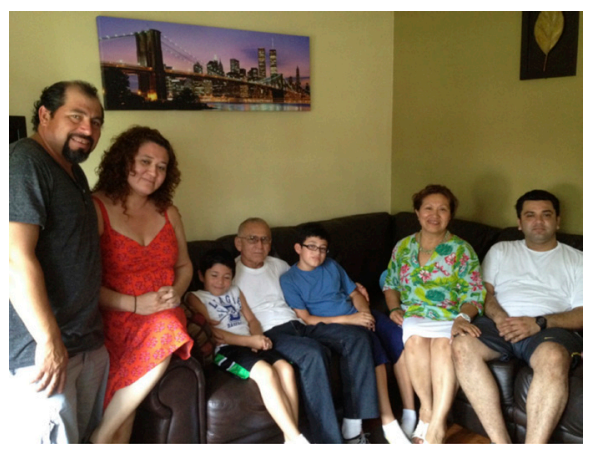




\section{Un patriarca que vive con el corazón entre dos tierras}

José Chávez recién cumplió 71 años. Se ufana de su buena salud, aunque de vez en cuando se le sube la presión arterial — dice_- especialmente cuando atestigua injusticias.

Recuerda como si hubiera sido ayer, hace 27 años, cuando decidió dejar El Salvador y emprender un viaje hacia "el norte". Confiaba en que su experiencia como mecánico automotriz y de aviones y como conductor del transporte público le serviría para darle un mejor sustento a su esposa Magdalena y sus dos hijos, Patricia y Boris.

Le había prometido a Patricia hacerle la mejor fiesta de 15 años que pudiera haber imaginado. Así que la mañana del 28 de diciembre de 1985 se montó a un bus, sin guía y sin "coyote" al que creía su nuevo hogar: Houston, Texas.

Cinco días después llegó a Matamoros. Estuvo por algún tiempo en Houston pero no le gustó lo suficiente para que allí viviera su familia. Así que agarró un avión hacia Nueva York, sin conocer a nadie. Le pidió a un taxista que le ayudar a averiguar dónde había una sede de Alcohólicos Anónimos, ya que, aunque él no bebía, sabía que ellos podrían ayudarle. Así, llegó a Hempstead.

Al principio fue muy difícil, recuerda sentado en la sala de la casa de su hija. Aunque había ofertas de trabajo como mecánico no tenía herramientas. Al fin, un dominicano le confió su equipo y pudo empezar a ganarse la vida.

"Para mí, cuando me mandaba 20 o 40 dólares... ¡era bastante!” —recuerda Magdalena, su esposa - Ella trabajaba en la empresa Texas Instruments, en San Salvador, que había comenzado a disminuir las jornadas laborales debido a la guerra.

"Mi hija — sigue diciendo con lágrimas en los ojos — estaba triste porque sus compañeras de colegio le contaban que sus papás que se habían ido a Estados Unidos terminaban haciendo otros hogares".

Cuando José pudo arreglar su situación migratoria con el patrocinio de la empresa donde ha trabajado prácticamente tres décadas, decidieron que fuera su esposa la

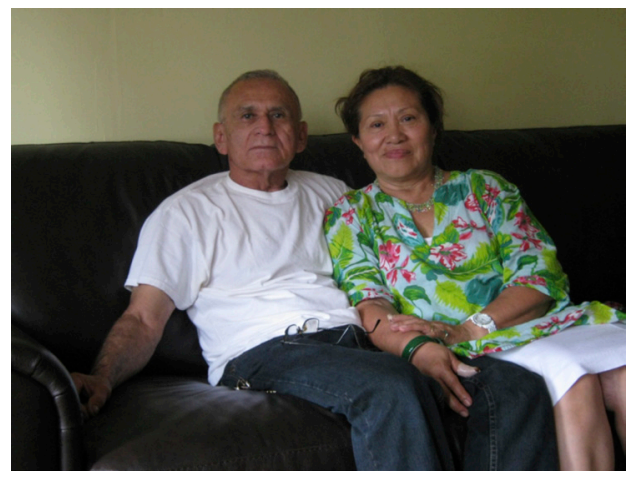
que viajara primero, aun sin contar con documentos; y los padres de ella quedarían a cargo de Patricia y de Boris, en ese entonces de 10 y 8 años, respectivamente. La Navidad de 1986 fue devastadora para todos.

En 1990 pudieron realizar el sueño de la Fiesta Rosa de Patricia. Pero todos estaban con un nudo en la garganta. Dos años después, los jóvenes pudieron reunirse finalmente con sus padres, con toda su documentación en regla. 


\section{No vas a limpiar casas}

José y Magdalena han sido testigos de la transformación de Long Island, especialmente de Hempstead y Freeport, donde han vivido. Hace tres décadas los únicos hispanos entre una población blanca y negra eran cubanos y portorriqueños.

“Antes deseábamos los frijolitos y las tortillas” — cuenta ella—. En los 'Delis' de comerciantes cubanos apenas conocían las hierbas y especias. Ahora, la población salvadoreña ha eclipsado a la boricua: según datos del Censo más reciente, para 2011, los salvadoreños sumaban 99.495 y los boricuas 88.514. Todo ello explica la proliferación de negocios de toda clase en manos de centroamericanos.

El crecimiento de la población salvadoreña es tan evidente que desde 1998 se creó un consulado en Garden City, en el condado de Nassau. En el condado de Suffolk, en Brentwood, funciona otro desde 2000. No obstante, el corazón de la comunidad es Hempstead, donde cada año se celebra el Día del Salvadoreño-Americano - en coincidencia con las fiestas agostinas de San Salvador- con un festival.

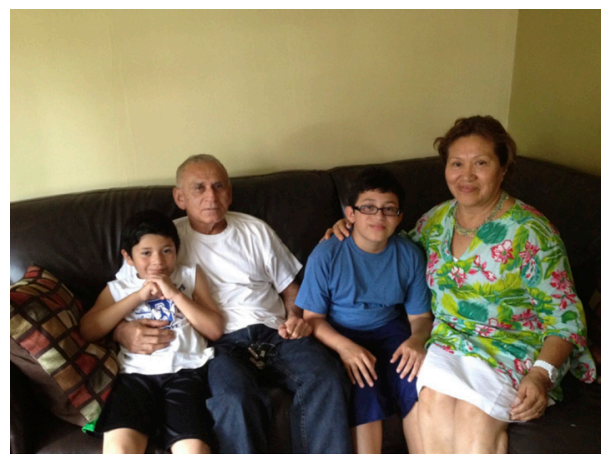

Magdalena ha trabajado limpiando casas durante más de 20 años. Ella recuerda que un día llevó a su hija a donde una de sus patronas, y ésta le dio un consejo: "No la traigas más. Sino, ella terminará haciendo lo mismo". Magdalena entendió la dimensión del mensaje, y creció en ella la aspiración de que sus hijos fueran profesionales. "Gracias

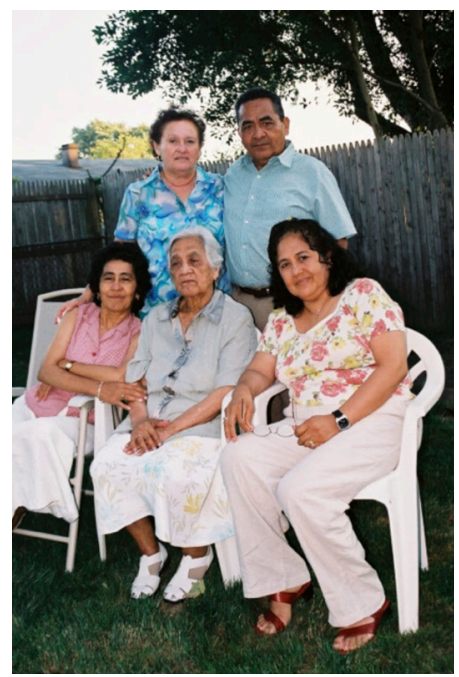
a Dios — responde - eso se hizo realidad": Patricia no solo es profesional sino que además es la primera salvadoreña en ocupar un cargo público en la Villa de Hempstead. Patricia, quien funge como titular del Department of the Village Clerk desde hace más de un año, está casada con el guatemalteco Álvaro Pérez; y tienen dos hijos.

Magdalena considera que es importante preservar en sus nietos (su hijo Boris tiene dos niñas y un niño) el conocimiento y aprecio por la cultura y las costumbres, como las religiosas (celebración del Divino Salvador del Mundo en agosto, El Salvador) y la Independencia, tanto de Guatemala como de El Salvador. 
José y Magdalena tienen un “conflicto" respecto a su jubilación. Quisieran pasar el resto de sus días en El Salvador; pero están conscientes que allá no podrán gozar de los beneficios médicos y sociales por los que han trabajado aquí.

Mientras la decisión llega, el patriarca de los Chávez disfruta viendo crecer su familia y atendiendo a su clientela, su mayor satisfacción.

\section{Los Coreas, un clan de cinco generaciones}

Marta Elisa Guerra nació en Honduras. A finales de los años 60 conoció al salvadoreño Víctor Manuel Coreas, pero en esa época no soplaban buenos vientos para su amor: se intensificaba el conflicto social y económico entre Honduras y El Salvador que desembocó en la “Guerra de las 100 horas”, en julio de 1969.

Víctor tuvo que regresar a El Salvador y Marta Elisa se reunió con él en agosto del año siguiente. Allí se casaron y nacieron sus tres hijos.

Con la guerra civil en El Salvador en pleno apogeo, intercalando mudanzas entre Santiago de María (Usulután) y San Miguel, ambos en el oriente del país, la familia Coreas Guerra decidió huir a San Pedro Sula, Honduras. En ese entonces, una hermana de Víctor, Ana Lilian, quien emigró hacia Nueva York en 1970 — después de haber sido expulsada de Honduras en el contexto del conflicto con El Salvador- había iniciado ya la petición de toda su familia. Ella es en realidad la gran raíz de un árbol que ya alcanza cinco generaciones.

Pasaron cinco años y los Coreas Guerra estaban establecidos en Honduras - como recuerda Marta Elisa - Pese a ello, accedieron a emigrar hacia Estados Unidos. "El gran cambio - de venir a Estados Unidos - era frustrante. En Honduras estábamos establecidos. No vivíamos con lujo, pero sí con comodidades... aquí tuvimos

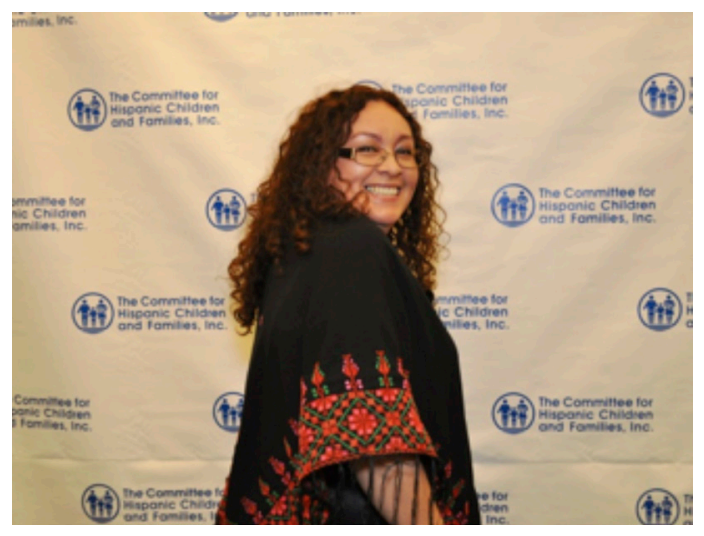
que venir a vivir en un basement (Brentwood), sin muebles. Tuvimos que comenzar de cero... ¡hasta cosas usadas compramos!"-cuenta-.

Nunca, nunca se arrepentirá - dice - de haber dejado Honduras, ya que Estados Unidos le ha dado la posibilidad de ver y desarrollarse a sus hijos y nietos, aprovechando oportunidades y beneficios. Su hija mayor, Karla, quien labora en una organización humanitaria, es una reconocida poetisa y editora, que, además de haber publicado ya varios libros, es convocada con frecuencia a festivales literarios en América Latina y Europa. 
Para Karla, vivir con tres herencias culturales es enriquecedor. "Cuando era niña me hice muchas preguntas, viviendo en este país. Cuando me decían: ‘De dónde vienes?’; yo decía: ‘de Honduras'. Cuando alguien comentaba: ‘pero que acaso no eres salvadoreña?’. Entonces yo le decía: ‘¡bueno, me han preguntado de dónde vengo no dónde nací!’. Luego opté por siempre decir que soy salvadoreña porque no tenía recuerdos de Honduras. Siendo hija de una hondureña, la comida en casa siempre fue estilo hondureño y de la costa; sopa de mariscos con coco, por ejemplo...; pupusas no las comía como la mayoría, solo de vez en cuando que íbamos a alguna pupusería cuando empezaron a llegar esos negocios a Brentwood, donde viví mi adolescencia”.

Confiesa que la cultura norteamericana la aprendió, pero no la hizo suya. "Siempre quise mantener mis raíces. Insistí en hablar español; y desde mucho antes de hacerlo profesionalmente hacía traducciones, porque quería practicar usar los dos idiomas" -indica-.

\section{Parlamento centroamericano... en casa}

De su padre, Marta Elisa recuerda que siempre le hacía ver las limitaciones y le advertía que nunca podría encontrar un hombre que la quisiera, porque éstos siempre quieren a su lado alguien que los atienda. "Yo tengo un defecto físico: me falta un brazo. Aquí me ofrecieron prótesis, pero nunca quise" - comenta - . Aquel no fue un impedimento para continuar ofreciendo sus servicios de belleza y costura. En la primera semana de trabajo ganó \$4.50 la hora. Allí trabajó por 11 años, alcanzando mejor paga y prestaciones.

Dejar el terruño no ha sido fácil, pero a esto Marta Elisa le pone buena cara. Le fascina cocinar comida tradicional hondureña, como las tortillas, sopa de jaiba o de caracol y tamales, aunque de la receta original de la masa de estos ultimos suprime el arroz, y terminan siendo más al estilo salvadoreño, con carne, "recaíto", garbanzos y chícharos.

Ana Lilian, la tercera hija de doña Raquel Coreas - la matriarca, de 87 años-, sin haber cumplido la mayoría de edad fue la pionera en emigrar. Su sueño de ser maestra fue truncado por la guerra entre El Salvador y Honduras. Haciendo malabares legales y económicos logró llegar a Nueva York; y junto a dos primas — como decenas de inmigrantes hispanos - logró ubicarse pronto en las factorías textiles de Manhattan y vivir en Long Island (Levittown).

En 1981 logró traer a su madre. Compraron una casa familiar en 1983; y para 1985 su hermano Víctor, su esposa Marta Elisa y sus tres hijos fueron los últimos en emigrar.

La familia entera se adaptó, creció y prosperó. Una reunión familiar fácilmente puede llegar a las 50 personas; una suerte de "naciones unidas" donde hay hondureños, salvadoreños, guatemaltecos, nicaragüenses, estadounidenses, dominicanos, brasileros, mexicanos, peruanos y hasta europeos. 
Sus raíces se han extendido desde Brentwood y Bay Shore, hasta Queens, Central Islip, Manhattan, y en otros estados como New Jersey, Georgia y Texas.

(*) Marta Elisa Guerra falleció el 23 de enero de 2013

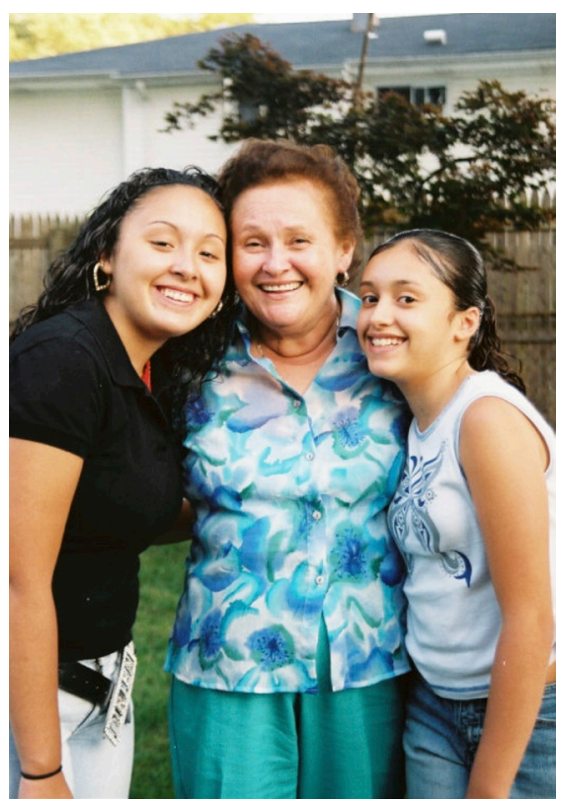




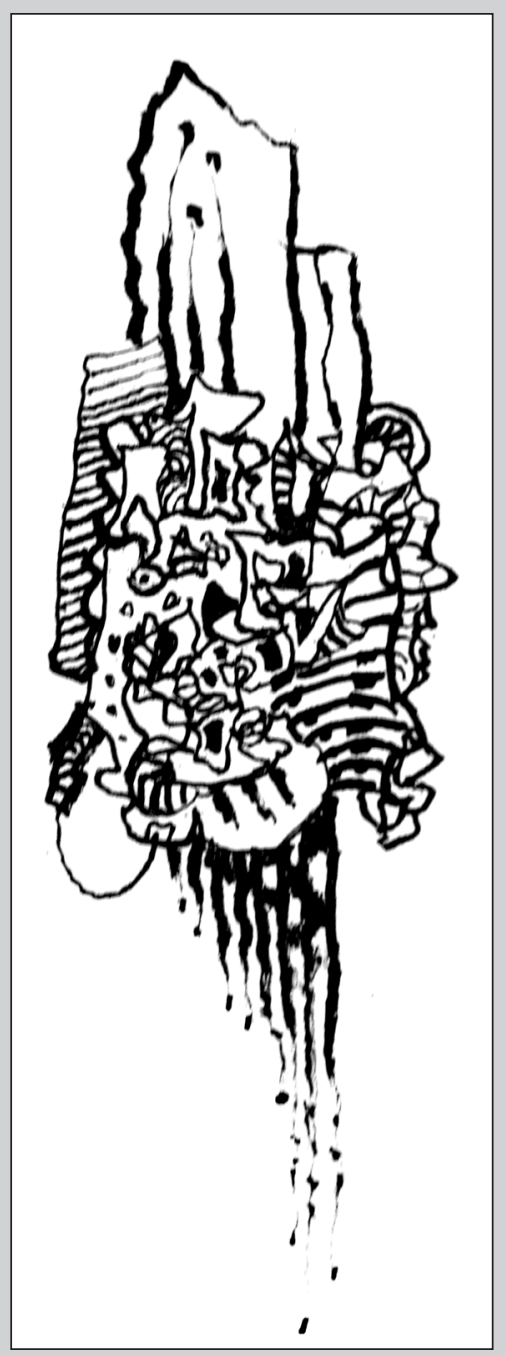

